This is an original manuscript of an article published by Taylor \& Francis in Studies in Higher Education on 13 June 2019, available online:

https://www.tandfonline.com/doi/full/10.1080/03075079.2019.1630813

\title{
A Narrative Literature Review Process for an Academic Business Research Thesis
}

Mari Juntunen ${ }^{\text {a* }}$ and Mirjam Lehenkari ${ }^{\mathrm{b}}$

${ }^{a}$ Department of Marketing, Management and International Business, University of Oulu, Oulu, Finland; ${ }^{b}$ Department of Economics, Accounting and Finance, University of Oulu, Oulu, Finland

*corresponding author, Dr Mari Juntunen, Senior Research Fellow, Department of Marketing, Management and International Business, Oulu Business School, P.O. Box 4600, 90014 University of Oulu, Finland, mari.juntunen@ oulu.fi

Dr Mirjam Lehenkari, Senior Lecturer, Department of Economics, Accounting and Finance, Oulu Business School, P.O. Box 4600, 90014 University of Oulu, Finland

\section{To cite this article:}

Juntunen, Mari \& Lehenkari, Mirjam (2019) A narrative literature review process for an academic business research thesis. Studies in Higher Education, DOI:

$\underline{10.1080 / 03075079.2019 .1630813}$ 


\section{A Narrative Literature Review Process for an Academic Business}

\section{Research Thesis}

Research on the systematic literature review process is extensive, but a justified explanation of how a narrative literature review process progresses remains absent from the existing literature. The purpose of this study is to increase understanding about the narrative literature review process. By building on process theory and the literature on systematic literature reviews and by empirically examining the literature review processes for bachelor's theses in a European business school, we reveal that a narrative literature process is iterative, non-structured and multi-layered; contains several cumulative written outcomes; and is embedded in a social context wherein various official and non-official actors guide and support the beginning researcher. This study is a fresh attempt to explain the progress of a literature review process with help of process theory, thereby offering novel insights into the research on literature reviews in general and on narrative literature reviews across various fields of human sciences specifically.

Keywords: process theory; narrative literature review; systematic literature review; bachelor's thesis; qualitative research

\section{Introduction}

A literature review provides the basis for all academic research. Researchers recognise a spectrum of literature review types, varying from very formulaic, systematic approaches to unsystematic narrative overviews. A systematic literature review refers to 'sequential steps to collect, know, comprehend, apply, analyze, synthesize, and evaluate quality literature in order to provide a firm foundation to a topic and research method' 
(Levy and Ellis 2006, 182). Systematic reviews aim to test a theory and they are typical in natural sciences (Xiao and Watson 2019). A narrative literature review, on its part, refers to a comprehensive narrative synthesis of previously published information (Green, Johnson and Adams 2006). Narrative reviews aim to build theory (Baumeister and Leary 1997) and they are typical in the humanities and social sciences, including management research (Tranfield, Denyer and Smart 2003; Becher 1994; Pickering et al. 2015).

The existing literature (e.g. Durach, Kembro and Wieland 2017; Xiao and Watson 2019) offers very detailed guidelines for how to conduct a systematic literature review. Despite some valuable general guidelines (Baumeister and Leary 1997) and suggestions for structuring the review (Green, Johnson and Adams 2006), questions such as how a narrative literature review process progresses and why it progresses as it does are inadequately addressed in previous studies. This is a major gap, specifically from the viewpoint of beginning researchers who often face many challenges in conducting a narrative review (see Chen, Wang and Lee 2016).

The objective of this study is to increase understanding about the narrative literature review process. To reach this aim, we build on process theory (e.g. Langley 1999; Van de Ven 1992), which gives us a basis to examine a narrative literature review as a social process consisting of cumulative and iterative steps. To the best of our knowledge, no previous research on literature reviews builds on process theory. We identify the feasible steps of the process on the basis of the existing research on systematic literature reviews and empirically examine the narrative literature review process of bachelor's theses in a European business school during 2018-19. This study contributes to the existing literature by offering a clear roadmap with practical steps for 
conducting narrative literature reviews, thereby enhancing the role of the narrative literature review across various fields of human sciences.

The paper begins by revisiting process theory and reviewing the existing research on literature review processes. The methodological section describes our empirical setting, data and analyses, followed by the results. The study closes by discussing the importance and limitations of the results, as well as by identifying future research avenues.

\section{Conceptual background}

\section{Process theory}

Process theory differentiates developmental and variance processes. The former provides explanations for the dynamic sequence of actions, events, stages or phases that unfold and the actors who are involved in the process of the central entity's existence over time, leading to an outcome; the latter explains causal relationships between independent and dependent variables (Langley 1999; Van de Ven and Poole 2005; Van de Ven 1992). We build our approach on developmental process theory as it is well suited to examining literature review processes. Although process theory was originally developed for examining organisational development and change, researchers acknowledge that social entities and processes not only occur at the organisational level but also at individual and group levels (Langley et al. 2013).

Providing a developmental process theory explanation relies on deep, unobservable process theory structures in the form of a generic story, which, at minimum, describes a progression or sequence of events and includes a clear beginning, middle and end (Pentland 1999). Two typical abstract ideal types of theories of change processes help identify this kind of explanation: life-cycle process theory and teleology 
process theory (Van de Ven 1992). Life-cycle process theory suggests that the underlying logic of a process, from its beginning to the final end state, is prefigured, consisting of a unitary, cumulative and conjunctive sequence of stages which must occur in a certain order (Van de Ven 1992; Van de Ven and Poole 1995). The systematic literature review process, entailing a specific sequence of actions that are to be concluded in order to reach the goal, reflects this line of thought. Researchers use visual maps or diagrams to demonstrate processes and their iterative dynamics; in illustrations, boxes usually represent states, phases or events and arrows represent flows (Langley et al. 2013; Van de Ven and Poole 1995).

Teleology process theory proposes that there are no prefigured rules and stages toward the goal (Van de Ven 1992). Although some vital steps or functions can be defined, the developing entity is purposeful and adaptive, socially constructs its envisioned end state and can achieve the goal via a number of alternative but equally effective paths, either by itself or in interaction with others (Van de Ven 1992; Van de Ven and Poole 1995). This often includes unpredictable and constructive movement back and forth between the stages (Juntunen 2015). As our empirical evidence suggests, the narrative literature review process builds on the logic of teleology process theory. We continue by reviewing the existing literature on literature reviews from the viewpoint of life-cycle process theory next.

\section{A literature review as a process}

We followed the guidelines for systematic literature reviews (see e.g. Okoli 2015; Webster and Watson 2002; Xiao and Watson 2019) in conducting a comprehensive search of the literature to find articles that specified the steps of the literature review process. We identified all the steps the existing literature referred to, and combining some closely related steps resulted in nine steps through which the 
phases of planning, conducting and reporting (Xiao and Watson 2019; Brereton et al. 2007) the literature review progresses, including possible iterations (see Figure 1).

- Insert Figure 1 here -

Selecting the topic starts the process (Pickering et al. 2015). A literature review can either focus on an emerging topic with the aim of establishing theoretical foundations or a mature topic that concentrates on analysing and synthesising the existing literature (Steward 2004; Torraco 2005; Webster and Watson 2002). Starting out with a too broad a topic, which needs to be narrowed down, is typical (Xiao and Watson 2019). Researchers (e.g. Green, Johnson and Adams 2006) advise preparing well before moving onto the next step by conducting preliminary searches of the literature and gradually refining the topic of the review.

Regarding defining the objective and formulating the research questions, a clear objective (Bearman et al. 2012) and a well-defined research question (or questions) (Xiao and Watson 2019; Steward 2004) guide all the other steps of the process. The objective of a thesis often is to summarise the state-of-the-art literature on the topic (Rowley and Slack 2004) or to describe it, but a literature review can also aim to test, extend or critique the existing research (Xiao and Watson 2019). The research question is very explicit in systematic literature reviews, but more ambiguous in narrative reviews (Bearman et al. 2012). As with selecting the topic, research questions are often too broad and need revising (Xiao and Watson 2019).

Developing and validating a review protocol is comparable to research design in empirical research (Xiao and Watson 2019). It contains a pre-set plan for how a researcher aims to conduct all the other steps of the research process (Gates 2002; Xiao 
and Watson 2019). Validation of the protocol by a more experienced person, such as a thesis supervisor, is essential.

Searching the literature contains four main aspects. First, articles in scholarly journals form the core of the literature review (Rowley and Slack 2004). These can be found via online databases, such as EBSCO, ABI/Inform (ProQuest), Web of Science and Google Scholar. The search terms, keywords (and their synonyms, abbreviations, alternative spellings) and related terms for the search stem from the research question (Xiao and Watson 2019). Second, conducting a search on a specific journal's homepage (see Webster and Watson 2002) may reveal articles that would not be discovered by a keyword search. Third, a backward search helps find supplementary articles from the reference list of each article and a forward search discovers articles that have cited the original articles (Xiao and Watson 2019). Fourth, the use of other scholarly publications, such as books (Rowley and Slack 2004) and conference papers (Webster and Watson 2002), depends on the objective of the literature review: they may be essential in a literature review with the purpose of describing what is known about the topic but unimportant in a literature review with the purpose of testing which only uses high-quality articles (Xiao and Watson 2019). Other practical search aspects include the publication language and date range of publications (Okoli 2015; Xiao and Watson 2019). Some researchers (e.g. Levy and Ellis 2006) suggest ceasing the literature search when new material is hard to find, whilst others propose continuing as long as the paper is published.

Selecting the literature refers to deciding which articles are included in the analysis or excluded from the analysis. The assessment is guided by the research question and is conducted by reading abstracts, skimming through the articles and making notes, all of which aid researchers pre-analyse and understand each study, and 
thus help build the analysis and synthesis around the most important studies on the topic (Xiao and Watson 2019).

Analysing refers to extracting data and making sense of it (Bearman et al. 2012; Okoli 2015; Xiao and Watson 2019; Randolph 2009). It includes reading and rereading the selected articles (Jabareen 2009); systematically mining the appropriate information from the articles (Okoli 2015); and coding concepts and themes either inductively or deductively (Xiao and Watson 2019) so that similar data are categorised and grouped together (Whittemore and Knafl 2005).

Synthesising is about organising the grouped data into a specific structure (Xiao and Watson 2019), often around themes or conceptual categories (Chen, Wang and Lee 2016). In systematic reviews, synthesising refers to using rigorous methodological approaches, such as a meta-analysis (Okoli 2015; Bearman et al. 2012), whilst in narrative reviews there is no one answer regarding what the structure of synthesis should be (Rowley and Slack 2004). Instead, a synthesis is framed through the expertise of individual researchers (Bearman et al. 2012) in order to organise the data into a structure that is either guided by a theory (Torraco 2005) or emerges from the literature (Rowley and Slack 2004) and is designed to actively search for contradictory findings and rival interpretations (Randolph 2009; Whittemore and Knafl 2005). A table, figure, diagram or matrix helps in illustrating the findings (Whittemore and Knafl 2005; Torraco 2005).

Concluding refers to the reviewer's analysis and interpretation of the findings (Steward 2004), representing higher levels of abstraction than the results (Whittemore and Knafl 2005). The conclusions include demonstrations of how the findings extend existing research, the implications for practitioners and academics, suggestions for 
further studies (Webster and Watson 2002) and the methodological limitations of the review (Whittemore and Knafl 2005).

Reporting refers to textually expressing the essential aspects of the review. The structure of the report varies depending on the outlet, but generally includes a title, abstract, introduction, methods, discussion, conclusion, list of references (Green, Johnson and Adams 2006) and in most cases also a description of the theoretical or conceptual background. The content of the reporting depends on the objective of the review as, for instance, a descriptive review presents the data as it is reported and extending review goes beyond the data (Xiao and Watson 2019). In each case, the report uses a clear, academic writing style (Torraco 2005). We empirically examine the existence of the above steps in the process of conducting a narrative literature review next.

\section{Methodology}

\section{Data}

We have years of experience in supervising hundreds of business research theses in a European AACSB-accredited university business school. This fits well with examining developmental processes, which often build on the lengthy involvement of researchers in the processes studied (Van de Ven 1992; Langley 1999). In line with developmental process research, our data consists of interviews and documentary data (Van de Ven 1992; Langley 1999; Van de Ven and Poole 2005) as they enable researchers to build interactional expertise on the topic, provide close access to the events and practices at hand, and help researchers describe the process (Langley et al. 2013; Pentland 1999).

We conducted three group interviews with nine supervisors in summer 2018 and three group interviews with seven volunteering students in December 2018. All of them 
participated in the school's bachelor's thesis process during the spring term 2018, which was in the third year of the students' studies. We chose group interviews as they allow for the efficient use of resources (Frey and Fontana 1991) and because the group dynamic may add valuable insights to the depth and dimension of the knowledge gained (Goldman 1962; Vaughn, Schumm and Sinagub 1996). Each group size equated the size of an informal conversational group (Edmiston 1944).

The interview outline included some general questions, such as questions about the success factors and challenges in supervising/conducting bachelor's theses, as well as specific questions concerning the steps of the literature review process. We considered the interview as a meaning-making conversation (Holstein and Gubrium 2016, 70) and emphasised active, responsive interviewing by asking further questions from the interviewees (Rubin and Rubin 2011, xv). Altogether seven hours of interviews were audio recorded and transcribed into over one hundred pages of text. The transcriptions were verified by the interviewees.

The documentary data contains graphic illustrations from each interviewee on how they perceived the iterative process; 125 bachelor's theses published in May 2018; pre-existing written material for the students, including generic guidance on the process of conducting a bachelor's thesis, instructions for the style of writing and guidelines for the outputs (the research plan, the mid-point report, the manuscript and its presentation, the final report) of the process; and open-ended written feedback on our preliminary narrative process illustration, gathered using Webropol software from 25 students who participated in the bachelor's seminar introductory lecture in January 2019.

\section{Analyses}


The analysis utilised various sensemaking strategies (Langley 1999) in order to explain how a developmental process (Pentland 1999) for conducting a narrative literature review for a bachelor's thesis progresses. First, we analysed the structure of the process (Larty and Hamilton 2011) using a theory-driven analysis (Langley 1999) in terms of the systematic literature review; that is, we identified how different conceptual steps of the process in Figure 1 existed in the data. We soon recognised that, although both the students and supervisors acknowledged a variety of steps, the actual process was much more complex than the conceptual process.

Therefore, we continued with a theory-driven analysis in terms of developmental processes with the aim of describing and explaining the beginning, middle and an end of the process; various actors involved; critical events and turning points; foundational patterns that give an overall direction to the process; causal factors that influence the sequencing of events; and the iteration cycle (Van de Ven and Poole 2005; Pentland 1999; Van de Ven 1992). Building on the ideas of teleology process theory, we specifically tried to illustrate a number of alternative but equally effective paths to reaching the goal (Juntunen 2015; Van de Ven 1992). Finally, we moved back and forth between the data and conceptual framework in order to build a generic story (Pentland 1999) that also covers contradictory findings and rival interpretations (Randolph 2009; Whittemore and Knafl 2005). The next section presents the results of our analyses.

\section{Findings}

\section{From linear process illustration to iterative process illustration}

Out of the 125 bachelor's theses analysed, less than a third included an explicit description of the process of the review. Without an exception, the illustrations were textbook examples of a systematic literature review process. Obviously, the students 
were incapable to define their approach since virtually all of the theses were narrative by their nature.

The interviewed students and supervisors who participated in the process in 2018 recognised all the steps of the conceptual process (see Figure 1). However, the students almost immediately realised that their process had not been that straightforward. One of the them described the process as follows:

It [the process] is not that simple [as the conceptual framework] -- it really does not go that way. -- You analyse the information [from literature searches] and then you might notice that something is missing which you need for the analysis, and then you'll search for more literature. -- When you find the literature, you may recognise that you need to change your research questions, or you start to think if the question is relevant on the basis of the existing literature. -- And then you analyse the material again and recognise that 'Okay, I could revise my research questions" -- and the same applies to synthesising. (Student C)

Other interviewees instinctively expressed the iterative and cumulative nature of the process. Student B stated: 'The process kind of goes around all the time' (Student B), meaning that a student moves from one step to another and back again and in no specific order until the thesis is ready. Student G continued: 'There are many steps that circulate; you get to some point and recognise that "This does not work", then you get back and do it again'. After reflecting on the conceptual framework depicted in Figure 1, Supervisor F declared: 'This should rather be described as a hermeneutic circle'.

Our data thus revealed that a narrative literature review process is iterative, nonstructured and multi-layered and that it comprises of several cumulative written outcomes. Figure 2 demonstrates that choosing a topic initiates the process and a 
bachelor's thesis is the final outcome of the process. Between these two ends, four partially overlapping steps iterate: exploring the literature, (re)defining the focus, analysing and synthesising, and writing. The students undergo each step several times during the process, sometimes simultaneously and not in any prescribed order. This is illustrated with wide arrows in Figure 2. The importance and respective weight of each step varies depending on the phase of the process in terms of written outputs, which include: a research plan, a mid-point report, a preliminary thesis manuscript (along with its oral presentation) and a final thesis. Thin arrows in Figure 2 illustrate how these four outputs integrate into the process. From the squared boxes in Figure 2, it is evident that the supervisor has an essential role throughout the process, and the supporting role of other actors varies depending on the stage of the project.

\section{- Figure 2 here -}

Introducing a sketch of Figure 2 to the next year, that is 2019, bachelor's seminar students revealed that the majority of them considered that, despite 'the fairly large number of arrows' (anonymous student comment \#12), the illustration helped them to understand the essential steps and their interconnections: 'The figure helps clarify that literature review is a process where the steps need to be repeated several times and that a research process does not proceed in any specified order' (anonymous student comment \#5). Many students considered the figure 'to be enlightening' (anonymous student comment \#9) and "to conveniently give the "big picture"" (anonymous student comment \#8). We will discuss the process in detail next.

\section{Choosing a topic}


Choosing a topic refers to selecting a subject for the thesis. The students are allowed to choose the topic by themselves because 'in that way the work progresses more efficiently' (Supervisor A). Similarly, the students think this is a good practice because they 'wanted to find an interesting topic on which it is pleasant to write' (Student A).

Yet many of the students considered choosing a topic challenging and changed the topic several times. An interesting topic can be found for example from course material, existing theses or through discussions with the supervisor. Sometimes older students had advised the younger ones to 'think about the topic early enough; thus, I had listed the topics on the note-taking app of my phone during the whole autumn' (Student F). A topic can also arise from everyday life, such as from work, hobbies, family and friends as well as traditional and social media.

Some of the students presupposed that the topic needs to be timely in terms of practical life, but the supervisors pointed out that this kind of thesis 'is more challenging to conduct' (Supervisor D) because 'there is lack of scientific research on the topic and, in my opinion, there has to be a lot [of existing literature] before I encourage students to start writing about it' (Supervisor E). Overall, the supervisors did not consider it a problem if many students were interested in the same topic: 'I supervised three [theses about the same topic] and each of them turned out to be totally different' (Supervisor B). However, Supervisor G 'encouraged students to study something "crazy"' in order to avoid the students studying similar topics.

Relationships with other steps. Many of the students changed or redefined the topic several times after their initial literature searches mainly because they were unable to find scientific literature on the topic. The supervisors mentioned that this often relates to finding the proper scientific terms and discussions: 
Finding the specific scientific discussion is a tough job, and if you can get them [the students] to understand it, you have done well, although it may take quite a long time. -It takes a while for students to recognise the difference between science and practical phenomena -- it is a huge leap in thinking for them to find a scientific discussion instead of coming to my office saying that it [the topic] has not been studied. Yes, it has. But they have to find the discussion. (Supervisor G)

\section{Exploring the literature}

Exploring the literature refers to getting oneself familiar with the existing literature on the topic. Our data suggests that in a narrative literature review, this consists of an intertwined combination of searching, evaluating, selecting, pre-analysing and reading the literature.

In terms of searching the literature, our students participate in an information retrieval training offered by the university library. Along with academic databases, the library personnel as well as supervisors encourage the use of a backward search as it helps the students to 'quickly find which [articles] most authors cite' (Supervisor C), as well as the use of Google Scholar because it usually 'helps you to find the most relevant [articles]' (Supervisor D). Searching takes an enormous amount of time and requires various rounds of searches. The students expressed that the supervisors could emphasise more that searching is such a crucial part of the process. They felt that 'it [the literature search] process was presented to us as being too simple - that you just choose some articles and move forward; indeed, it does not go that way' (Student B).

The students learn to critically evaluate literature along with their literature search during the library training, which is probably the reason why they did not explicitly discuss about the issue in the interviews. The supervisors, for their part, noted 
that for some of the students, critical evaluation is challenging: 'the source material contains more, well - they are scientific publications but of low quality. Students are unable to recognise what's high [quality] and what's not' (Supervisor B). The students are also inclined to use non-academic references such as newspapers, market research and other content from the internet. Although in some rare cases, when the topic is novel, some of the supervisors let the students include 'blogs as references in a literature review, even though I find it a bit questionable' (Supervisor I), they are generally very strict in this.

Selecting the relevant literature for the thesis is demanding: students may have dozens of articles without comprehension of what to do with them. However, many were confident in selecting articles and chose 'something that supported it [what the student had found so far] or something which contradicted it in order to get some discussion between them' (Student C).

We highlight the role of pre-analysing because some of the students expressed that they simultaneously conducted analysing with the literature search: 'When you select articles, you simultaneously analyse them and take notes, and there will definitely be no time for a separate analysis phase' (Student B)

Reading is also closely connected to searching: 'You search the literature, you read the texts, and they are interwoven.' (Student G). Although the students recognised that reading is essential part of the process, they were surprised by how laborious and time-consuming it can be.

Relationships with other steps and outcomes. Student C highlighted the importance of the literature search as it 'suggests what I can study and what information already exists before I set my objective'. In the beginning of the process, getting oneself familiar with the literature often leads to redefining the focus of the review: 
I searched for literature, and then I wrote down something. And then I went back to the research question and started to search for new material. I did this repeatedly, but at some point you just need to stop and finalise [the thesis]. (Student G)

A literature search also relates to writing. As described earlier, the students wrote notes while exploring the literature. Although some considered this convenient, others found it challenging and suggested emphasising the literature search before writing. Both the supervisors and students recognised that sometimes the most essential references are found as late as at the end of the process. Although exploring the literature is an extremely imporant part of the process, both the students and supervisors recognised that at some point the active search needs to be stopped in order to finalise the thesis.

\section{(Re)defining the focus}

(Re)defining the focus refers to (re)formulating the objective and the research question(s). Somewhat surprisingly, only one interviewee highlighted the objective of the research: 'It was unbelievably difficult to set the objective and research questions. And they both changed during the process' (Student C).

Instead, considerable attention was dedicated to research questions. Although some of the supervisors considered formulating a research question to be essential at the beginning of the process because 'you need to have a viewpoint from which you approach [the phenomenon], and thus a reasonable question' (Supervisor B), others acknowledged that the questions typically sharpen or even change during the process. As Student B expressed it: 'Perhaps research questions have too much weight at the 
beginning because my original and final research questions addressed two totally different issues'.

Relationships with other steps. At the beginning of the process, research questions typically evolve with new information from literature searches:

It was quite surprising that when you gained more information, the research questions changed a lot. -- I think my first question was too broad and not focused enough. And when you understand that it's really difficult to do anything with a broad question, you realise that you need to focus much more, and then it became much easier [to proceed]. (Student E)

Research questions also change due to analysing and synthesising, as already shown above. Furthermore, not only the questions but even the title can change at the end of the writing process in order to better fit the content of the thesis: 'I changed the title at the very last moment when I returned the final version. It [the process] culminated in that'. (Student G)

\section{Analysing and synthesising}

Analysing refers to deconstructing and investigating the data and synthesising is about reorganising the scattered data. As described earlier, analysing can either be embedded in exploring the literature or considered as a distinctive step that comes after it. It was widely agreed that analysis precedes synthesising: 'To me they [analysis and synthesis] are two different things because it is very important for you to understand the subject and related concepts first, before you start pulling together information' (Student C). 
Relationships with other steps. Many of the students considered synthesis to be a turning point before which 'other steps of the process have been iterated' (Student B). Analysing is linked to reading and writing: 'When you start sketching the synthesis, you [have to] go back to the article if you have not made good enough notes' (Student G).

\section{Writing}

Writing refers to a continuous process of producing different types of texts, varying from note-taking to polished scientific writings. While some of the students considered writing challenging, others did not: 'Basically, scientific writing is easy. It wasn't difficult to write out what I had absorbed from the articles.' (Student E). The students had a writing course along with the thesis seminar, and many students organised writing sessions on their own with their peers. Both the students and supervisors emphasised consistent expression throughout the report. The students found it confusing that the process of conducting a literature review does not follow the linear structure of the thesis:

I would have preferred to write in a specific order, but it really doesn't go that way. I felt bad that it [the introduction] was missing at the beginning [of the process], but you really cannot write it before you have an idea of what the outcome will be. (Student C)

Relationships with other steps and outcomes. Writing crystallises in cumulative written outcomes, which the supervisor and peers comment on and after which the process continues guided by these comments. The first written outcome is a research plan, which is usually written after choosing a topic, conducting preliminary literature search and formulating initial research question(s). After the research plan, the process usually continues by exploring the literature. The second output is a mid-point report, 
varying from approximately half of the final report to a full sketch of the final report, and after which the process usually continues with analysing and synthesising the gathered data. The third written outcome is a manuscript on which the student gives an oral presentation too. The presentation is an important part of the process as it helps students to find out if their manuscript contains incoherencies that make it difficult for outside readers to understand their text. Thereafter, the process usually continues with more writing: 'It was "just" finalising [the thesis], but it was probably one of the toughest stages of the process - having enough strength to refine the thesis.' (Student C). The fourth output is the final outcome of the process: a bachelor's thesis.

\section{Discussion}

The purpose of this study was to increase understanding about the process of conducting a narrative literature review. By building on process theory and the existing literature on systematic literature reviews, we specifically aimed at describing how a narrative literature review process progresses and explaining why it progresses as it does. Our empirical examination focused on the process of conducting a bachelor's theses in a European business school.

We showed that a narrative literature review process is iterative, nonstructured and multi-layered and that it contains several written outcomes. The process is embedded in its social context where specifically the supervisor but also other official and non-official actors guide and support the beginning researchers in their path.

Choosing a topic initiates the process and a written report, in the form of a bachelor's thesis, is the final outcome of the process. This observation is similar to the existing research on literature reviews (Pickering et al. 2015; Xiao and Watson 2019; Brereton et al. 2007). Between the start and end points of the process, four 
iterative steps (exploring the literature, [re]defining the focus, analysing and synthesising, and writing) - many of which are combinations of the steps identified in systematic reviews - alternate, and their order, importance and relative focus varies. This clearly differs from the linear process of conducting a systematic review. Of course, the linear process may also contain iterations (Levy and Ellis 2006; Xiao and Watson 2019), but our findings on narrative literature reviews fit better with teleology process theory wherein no prefigured steps exist (Van de Ven 1992), the process is socially constructed and the goal can be reached via a number of alternative but equally effective paths (Van de Ven 1992; Van de Ven and Poole 1995) and through unpredictable movement back and forth between the steps (Juntunen 2015).

Continuous writing is characteristic to a narrative literature review process. Several cumulative written reports and the knowledge gained from these steps help the students keep some logic in their multidimensional and multidirectional process. This finding illustrates a perspective on reporting that diverges from that of systemic reviews, which consider reporting as the last step of the process (Okoli 2015; Xiao and Watson 2019). Furthermore, analysing has a dual role both as an embedded aspect of exploring the literature and as its own step, alongside synthesising. Although systematic reviews recognise both of these roles (Xiao and Watson 2019), the dual role seems to be extremely important in narrative research.

\section{Implications}

\section{Theoretical implications}

Our study offers two important contributions to the extant research on literature reviews. First, with the help of teleology process theory, we explain how 
the process of conducting a narrative literature review progresses and why it progresses in that way. Researchers have described the various steps of the systematic literature review process (Brereton et al. 2007; Xiao and Watson 2019; Okoli 2015), but aside from some general guidelines (Baumeister and Leary 1997; Green, Johnson and Adams 2006), the research on narrative literature reviews has been silent about how the process progresses, at least from the viewpoint of teleology process theory. Our study fills these gaps and thus contributes to the research on narrative literature reviews across various disciplines in human sciences.

Second, by building on developmental process theory, we propose that the process of conducting a systematic literature review follows the logic of life-cycle process theory. Despite an extensive methodological interest in systematic reviews (e.g. Webster and Watson 2002; Xiao and Watson 2019), the existing research has lacked this kind of underlying explanation for the process. Our study fills this gap, thereby contributing to the research on literature reviews in general.

\section{Practical implications}

Previous knowledge on the standard steps of a literature review process is valuable yet confusing and insufficient for the purposes of narrative researchers. Our study offers an appealing framework for supervisors, students and researchers in general for conducting a narrative literature review. We emphasise that exploring the literature is an arduous and time-consuming task which each researcher should recognise and consider when preparing the research plan. We encourage researchers, thesis supervisors in particular, to contemplate the iterative and hermeneutic nature of the steps of the narrative literature review process that we 
have just described. One of the students noted that this may feel frustrating because it feels like the process rarely moves forward, not to mention ever ends. Therefore, the role of several cumulative written reports in supporting the progress of both the process and the final report should not be underestimated and be clearly written out in any guidelines for writing a thesis.

\section{Limitations and further studies}

Firstly, by focusing on bachelor's thesis students, we lack information on whether the process would be similar for more advanced students or researchers. Secondly, as the responses are from volunteering students alone they may exclude experiences which interviewing all the students would have covered. Furthermore, our rich data uncovered neither the role of the objective nor the structure of the synthesis in a narrative literature review. Finally, the embedded role of the authors in the research process can be questioned, although it is in line with conducting developmental process research (e.g. Langley 1999).

Questions that remain unanswered include: What are the similarities and differences between novice students and more experienced students in conducting a narrative literature review? How is the process of conducting a narrative literature review for a journal article similar to or different from the process described in this study? What are the roles of the objective and synthesis in a narrative literature review? We encourage researchers across human sciences to test and further develop our explanation for the narrative literature review process.

\section{References}

Baumeister, Roy F. and Mark R. Leary. 1997. "Writing Narrative Literature Reviews." Review of General Psychology 1 (3): 311-320. 
Bearman, Margaret, Calvin D. Smith, Angela Carbone, Susan Slade, Chi Baik, Marnie Hughes-Warrington, and David L. Neumann. 2012. "Systematic Review Methodology in Higher Education." Higher Education Research \& Development 31 (5): 625-640.

Becher, Tony. 1994. "The Significance of Disciplinary Differences." Studies in Higher Education 19 (2): 151-161.

Brereton, Pearl, Barbara A. Kitchenham, David Budgen, Mark Turner, and Mohamed Khalil. 2007. "Lessons from Applying the Systematic Literature Review Process within the Software Engineering Domain." Journal of Systems and Software 80 (4): 571-583.

Chen, Der-Thanq "Victor", Yu-Mei Wang, and Wei Ching Lee. 2016. "Challenges Confronting Beginning Researchers in Conducting Literature Reviews." Studies in Continuing Education 38 (1): 47-60.

Durach, Christian F., Joakim Kembro, and Andreas Wieland. 2017. "A New Paradigm for Systematic Literature Reviews in Supply Chain Management." Journal of Supply Chain Management 53 (4): 67-85.

Edmiston, Vivian. 1944. "The Group Interview." The Journal of Educational Research 37 (8): 593-601.

Frey, James H. and Andrea Fontana. 1991."The Group Interview in Social Research." The Social Science Journal 28 (2): 175-187.

Gates, Simon. 2002. "Review of methodology of quantitative reviews using metaanalysis in ecology". Journal of Animal Ecology 71 (4): 547-57.

Goldman, Alfred E. 1962. "The Group Depth Interview." Journal of Marketing 26 (3): $61-68$.

Green, Bart N., Claire D. Johnson, and Alan Adams. 2006. "Writing Narrative Literature Reviews for Peer-Reviewed Journals: Secrets of the Trade." Journal of Chiropractic Medicine 5 (3): 101-117.

Holstein, James A. and Jaber F. Gubrium. 2016. "Narrative Practice and the Active Interview." In Qualitative Research, edited by Silverman, David. 4th ed. Vol. 67, 67-82. London: Sage.

Jabareen, Yosef. 2009. "Building a Conceptual Framework: Philosophy, Definitions, and Procedure." International Journal of Qualitative Methods 8 (4): 49-62.

Juntunen, Mari. 2015. "Time-Based Modifications to Process Theory Illustrations through a Corporate Rebranding Case Study." Baltic Journal of Management 10 (2): 222-242. 
Langley, Ann. 1999. "Strategies for Theorizing from Process Data." Academy of Management Review 24 (4): 691-710.

Langley, Ann, Clive Smallman, Haridimos Tsoukas, and Van de Ven, Andrew H. 2013. "Process Studies of Change in Organization and Management: Unveiling Temporality, Activity, and Flow." Academy of Management Journal 56 (1): 1-13.

Larty, Joanne and Eleanor Hamilton. 2011. "Structural Approaches to Narrative Analysis in Entrepreneurship Research: Exemplars from Two Researchers." International Small Business Journal 29 (3): 220-237.

Levy, Yair and Timothy J. Ellis. 2006. "A Systems Approach to Conduct an Effective Literature Review in Support of Information Systems Research." Informing Science 9: 181-212.

Okoli, Chitu. 2015. "A Guide to Conducting a Standalone Systematic Literature Review." Communications of the Association for Information Systems 37: 879-910.

Pentland, Brian T. 1999. "Building Process Theory with Narrative: From Description to Explanation." Academy of Management Review 24 (4): 711-724.

Pickering, Catherine, Julien Grignon, Rochelle Steven, Daniela Guitart, and Jason Byrne. 2015. "Publishing Not Perishing: How Research Students Transition from Novice to Knowledgeable using Systematic Quantitative Literature Reviews." Studies in Higher Education 40 (10): 1756-1769.

Randolph, Justus J. 2009. "A Guide to Writing the Dissertation Literature Review." Practical Assessment, Research \& Evaluation 14 (13): 1-13.

Rowley, Jennifer and Frances Slack. 2004. "Conducting a Literature Review." Management Research News 27 (6): 31-39.

Rubin, Herbert J. and Irene S. Rubin. 2011. Qualitative Interviewing: The Art of Hearing Data. Third ed. Los Angeles: Sage.

Steward, Barbara. 2004. "Writing a Literature Review." British Journal of Occupational Therapy 67 (11): 495-500.

Torraco, Richard J. 2005. "Writing Integrative Literature Reviews: Guidelines and Examples." Human Resource Development Review 4 (3): 356-367.

Tranfield, David, David Denyer, and Palminder Smart. 2003. "Towards a Methodology for Developing Evidence-informed Management Knowledge by Means of Systematic Review." British Journal of Management 14 (3): 207-222.

Van de Ven, Andrew H. 1992. "Suggestions for Studying Strategy Process: A Research Note." Strategic Management Journal 13 (S1): 169-188. 
Van de Ven, Andrew H. and Marshall Scott Poole. 1995. "Explaining Development and Change in Organizations." Academy of Management Review 20 (3): 510-540.

Van de Ven, Andrew H. and Marshall Scott Poole. 2005. "Alternative Approaches for Studying Organizational Change." Organization Studies 26 (9): 1377-1404.

Vaughn, Sharon, Jeanne Shay Schumm, and Jane M. Sinagub. 1996. Focus Group Interviews in Education and Psychology Sage.

Webster, Jane and Richard T. Watson. 2002. "Analyzing the Past to Prepare for the Future: Writing a Literature Review." MIS Quarterly 26 (2): xiii-xxiii.

Whittemore, Robin and Kathleen Knafl. 2005. "The Integrative Review: Updated Methodology." Journal of Advanced Nursing 52 (5): 546-553.

Xiao, Yu and Maria Watson. 2019. "Guidance on Conducting a Systematic Literature Review." Journal of Planning Education and Research 39 (1): 93-112. 


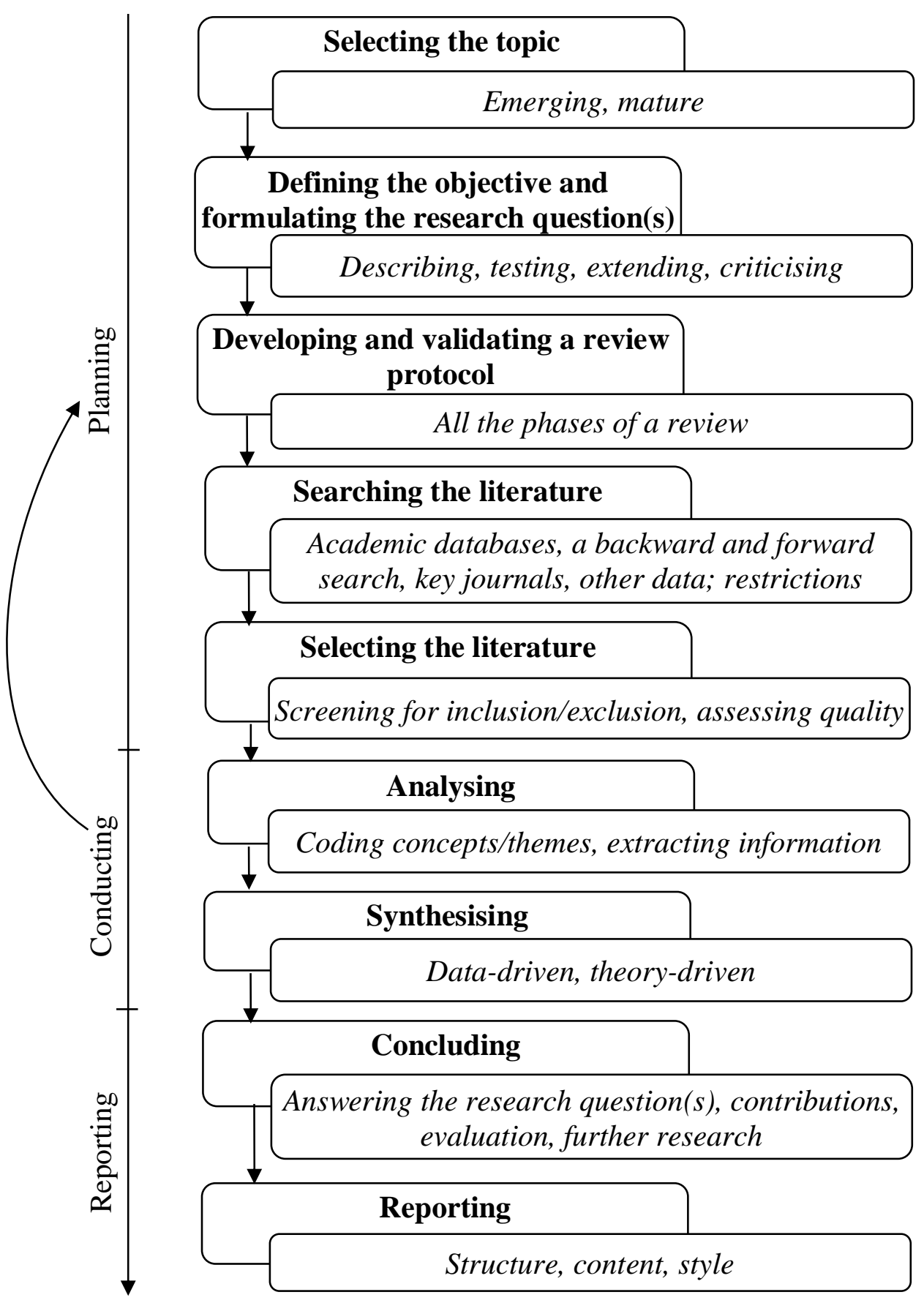

Figure 1. The literature review process in the existing literature 
Choosing a topic

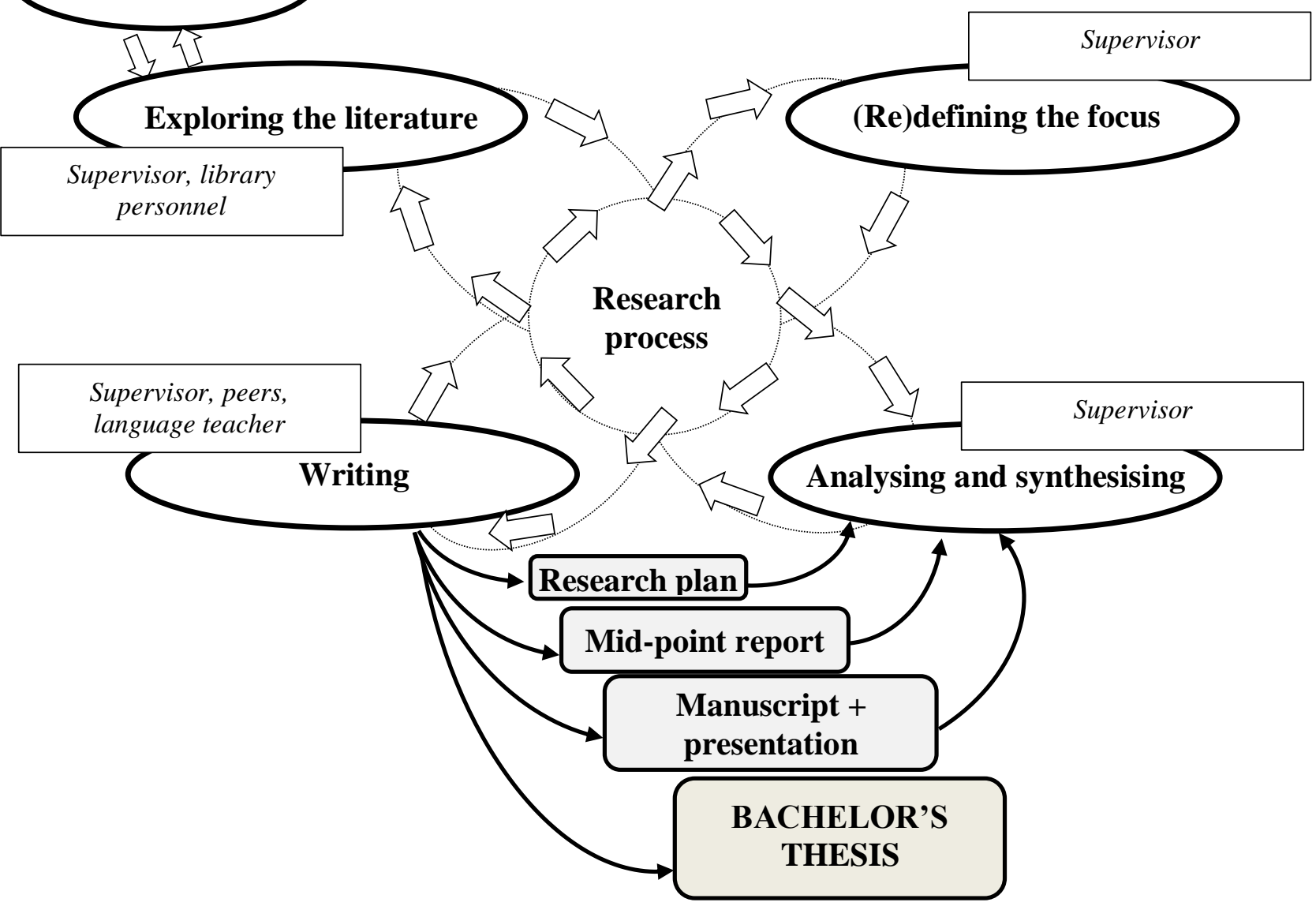

$\bigcirc$ Step $\square$ Outcome $\square$ Social actors $\longrightarrow$ Direction of the process

Figure 2: The narrative literature review process for bachelor's theses 